\title{
PROPRIEDADES FUNCIONAIS DAS PROTEÍNAS DE AMÊNDOAS DA MUNGUBA (Pachira aquatica Aubl.)
}

\author{
BERNADETE DE LOURDES DE ARAÚJO SILVA², \\ CLAUDIA CARNEIRO DE AZEVEDO 3 , \\ FÁTIMA DE LOURDES ASSUNÇÃO ARAÚJO AZEVEDO ${ }^{4}$
}

RESUMO - A semente da munguba (Pachira aquatica Aubl.) contém amêndoas que exibem um conteúdo excelente de óleo e um percentual significativo em proteínas. Propositou-se determinar algumas propriedades funcionais das proteínas de amêndoas da munguba com o objetivo de instituir sua utilização na indústria de alimentos. O teor lipídico foi de $46,62 \%$, o proteico de $13,75 \%$ e na forma de torta apresentou um índice de $28,27 \%$ de proteínas. Obtiveram-se dois isolados proteicos, o IP 2,0 e o IP 10,0, decorrentes de duas condições de $\mathrm{pH}(2,0$ e 10,0). Na obtenção dos isolados proteicos, os índices em proteínas extraídas foram de $38,52 \%$ para o IP 2,0 e $82,06 \%$ para o IP 10,0. Os índices de proteínas recuperadas através da precipitação isoelétrica foram de 23,35\% para o IP 2,0 e de 70,94\% para o IP 10,0, em $\mathrm{pH} 5,0$. As propriedades funcionais exibiram solubilidade mínima em $\mathrm{pH} 5,0$, no ponto isoelétrico (pI), sendo mais elevada em $\mathrm{pH}$ ácido e alcalino do pI. As melhores capacidades de absorção de água e de óleo exibidas foram para o IP 10,0. As propriedades emulsificantes foram dependentes do $\mathrm{pH}$ para os dois isolados, e o IP 10,0 indicou melhores resultados. As propriedades funcionais estudadas permitem o emprego dos isolados proteicos em produtos alimentícios que requerem alta solubilidade, tais como os produtos de panificação, massas em geral, sopas desidratadas e molhos, produtos que exigem desempenho na absorção do óleo, como as carnes simuladas, e em produtos que requerem poderes emulsificantes.

Termos para indexação: munguba, proteína, isolado proteico, propriedades funcionais.

\section{FUNCTIONAL PROPERTIES OF PROTEINS FROM ALMONDS OF THE GUIANA-CHESTNUT (Pachira aquatica Aubl.)}

\begin{abstract}
Seeds of the Guiana-chestnut (Pachira aquatica Aubl.) contain almonds with excellent oil content and a significant percentage of proteins. The aim of this study was to determine some properties of proteins from Guiana-chestnut almonds in order to propose its use in the food industry. The content of lipids was of $46.62 \%$, of proteins $13.75 \%$, and in the form of cake, it has showed a protein rate of $28.27 \%$. Two protein isolates were obtained, IP 2.0 and IP 10.0, resulting from two $\mathrm{pH}$ conditions (2.0 and 10.0). To obtain the protein isolates, the contents of extracted proteins were of $38.52 \%$ for IP 2.0 and of $82.06 \%$ for IP 10.0. The rates of proteins recovered by isoelectric precipitation were of $23.35 \%$ for IP 2.0 and of $70.94 \%$ for PI 10.0 at $\mathrm{pH}$ 5.0. The functional properties exhibited minimum solubility at isoelectric point $\mathrm{pH} 5.0$, being higher at acidic and alkaline isoelectric point $\mathrm{pH}$. The best water and oil absorption capacities were for IP 10.0. The emulsifying properties were dependent on $\mathrm{pH}$ for both isolates, and PI 10.0 showed better results. The functional properties studied allow the use of protein isolates in food products that require high solubility such as bakery products, pasta in general, dehydrated soups and sauces; products that require high performance in oil absorption such as simulated meat; and products that require emulsifying power. Index terms: Guiana-chestnut, protein, protein isolate, functional properties.
\end{abstract}

\footnotetext{
${ }^{1}$ (Trabalho 065-14). Recebido em: 13-02-2014. Aceito para publicação em: 15-08-2014.

${ }^{2}$ Nutricionista, Mestre em Ciência e Tecnologia de Alimentos pela Universidade Federal da Paraíba. E-mail: bernnaraujo@gmail.com ${ }^{3}$ Farmacêutica, Mestre em Ciência e Tecnologia de Alimentos pela Universidade Federal da Paraíba. E-mail: claudia_azevedo7@ yahoo.com.br

${ }^{4}$ Química Industrial, Doutora em Ciência e Tecnologia de Alimentos pela Universidade Federal da Paraíba. E-mail: fatimazevedo@ gmail.com
} 


\section{INTRODUÇÃO}

As proteínas vegetais são usadas nos alimentos como substâncias funcionais para melhorar a estabilidade e a textura, assim como a qualidade nutritiva do produto (MAKRI et al., 2005).

Propriedades funcionais de proteínas são importantes no processamento e na formulação do produto, uma vez que afetam a aceitação do consumidor. Algumas delas atuam na capacidade de absorção de água e de óleo, na emulsificação, na capacidade de formação de espuma e de geleificação. Essas propriedades dependem de características físico-químicas das proteínas, incluindo fatores, tais como peso molecular, composição de aminoácidos, carga líquida e hidrofobicidade (RODRIGUES et al., 2012). Com base nessas propriedades, a proteína específica é selecionada para ser usada em um determinado alimento e dependerá de sua função exigida no produto final (CHEL-GUERREIRO et al., 2002).

A disponibilidade, o custo e os fatores de risco, associados a doenças de fontes de proteína de origem animal, fazem com que os nutricionistas considerem as fontes de proteínas vegetais alternativas para preparação humana e matéria-prima. Nos últimos anos, muitas plantas têm atraído um grande interesse científico como fontes de proteínas de baixo custo para suplementar dietas humanas (YUN et al., 2005).

Pachira aquática Aublet (família Bombacaceae), vulgarmente conhecida como munguba, castanheira-do-maranhão, castanheira, cacau-selvagem, é uma árvore nativa do sul do México até o norte da América do Sul, na área compreendida pela floresta amazônica, onde pode ser encontrada frequentemente em terrenos alagadiços e matas ciliares; entretanto, apresenta a característica de facilmente adaptar-se às condições edáficas e climáticas diversas (PEIXOTO;ESCUDEIRO, 2002).

A munguba já tem sido assunto de vários estudos por pesquisadores, porém é pouco utilizada pelos brasileiros, não sendo reconhecida ainda como uma espécie de importância para a exploração econômica. Assim, o presente trabalho tem como objetivo caracterizar algumas propriedades funcionais em dois isolados proteicos das amêndoas da munguba, estabelecendo seu potencial como ingrediente funcional na indústria de alimentos.

\section{MATERIAL E MÉTODOS}

\section{Material}

As sementes da munguba (Pachira aquatica Aubl.) in natura foram descascadas e suas amêndoas levadas em estufa a $40^{\circ} \mathrm{C}$ por 24 horas, seguidas de trituração em liquidificador doméstico e tamisação em malha de 48 mesh. A farinha foi desengordurada com hexano em aparelho de Soxhlet.

\section{Componentes Centesimais}

As determinações de umidade, cinzas, proteínas e lipídeos foram realizadas seguindo a metodologia da AOAC (2005). O conteúdo de carboidratos totais, incluindo fibras, foi calculado por diferença de 100, inserindo o teor de fibras com a soma dos demais componentes.

\section{Obtenção dos Isolados Proteicos}

Dois isolados proteicos (IP 2,0) e (IP 10,0) foram obtidos em duas condições de $\mathrm{pH}$, o $(2,0)$ e o $(10,0)$, respectivamente. Os isolados proteicos foram adquiridos a partir da farinha desengordurada, à qual se adicionou água destilada na proporção de 1:20, pH equilibrado em 2 (IP 2,0) com $\mathrm{HCl} \mathrm{1,0}$ $\mathrm{N}$ e em 10 (IP 10,0) com $\mathrm{NaOH} 0,1 \mathrm{~N}$, seguido de agitação por 3 horas, a $5^{\circ} \mathrm{C}$. Em seguida, as amostras foram centrifugadas a 5.000 x $\mathrm{G}$ a $5^{\circ} \mathrm{C}$ por 30 minutos e filtradas, medindo-se o volume obtido. Duas reextrações foram feitas a partir do mesmo resíduo e sob as mesmas condições, obtendo-se mais dois sobrenadantes, que tiveram seus volumes determinados. Retirou-se uma alíquota de $1 \mathrm{~mL}$ para determinação de proteínas solúveis pela metodologia de Kjeldahl (AOAC, 2005). Juntou-se o conteúdo dos sobrenadantes, o $\mathrm{pH}$ foi ajustado para 4,5, para precipitação de proteínas. Centrifugou-se a $5.000 \mathrm{x}$ $\mathrm{G}$ a $5^{\circ} \mathrm{C}$ durante 30 minutos, obtendo-se um novo extrato. Os sobrenadantes resultantes da extração foram combinados, e o $\mathrm{pH}$ ajustado novamente para $\mathrm{pH} 4,5$. Este volume foi medido, e determinado o teor de proteínas por Kjeldahl (AOAC, 2005). O precipitado final foi congelado e seguido de liofilização para posteriores análises das propriedades funcionais.

\section{Propriedades Funcionais das Proteínas Solubilidade}

Para a determinação da solubilidade, utilizouse da metodologia de Bera e Mukherjee (1989) com modificações. As amostras dos isolados proteicos, equivalentes a $0,1 \mathrm{~g}$ em proteínas, foram dispersas em $20 \mathrm{~mL}$ de água destilada e equilibradas em $\mathrm{pH}$ de 2,$0 ; 4,0 ; 5,0 ; 6,0 ; 8,0$ e 10,0 , com $\mathrm{HCl} 1,0 \mathrm{~N}$ e $\mathrm{NaOH} 1,0 \mathrm{~N}$, sob agitação contínua, em agitador magnético, na temperatura ambiente. As proteínas 
solúveis foram quantificadas pelo método de Kjeldahl (AOAC, 2005).

\section{Capacidade de Absorção de Água e de Óleo}

A capacidade de absorção de água foi analisada pela metodologia de Bencini (1986) com modificações. As amostras equivalentes a $0,25 \mathrm{~g}$ em proteínas foram pesadas em tubos de centrífuga graduados, e um volume de 2,5 mL de água destilada foi acrescentado. Os tubos foram centrifugados a 2.750 x $\mathrm{G}$ durante $10 \mathrm{~min}$. Os volumes dos sobrenadantes resultantes foram medidos, e o resultado expresso em $\mathrm{mL}$ de água/g proteínas foi medido após a correção de proteínas solúveis.

A capacidade de absorção de óleo foi determinada segundo o método de Lin e Zayas (1987). As amostras equivalentes a 0,25 g em proteínas foram pesadas em tubos de centrífuga graduados e um volume de 2,5 $\mathrm{mL}$ de óleo de soja (marca SOYA, BUNGE ALIMENTOS S. A.), densidade de $0,923 \mathrm{~g} / \mathrm{mL}$ a $25^{\circ} \mathrm{C}$, foi acrescentado. Os tubos contendo as amostras foram centrifugados em separado a 2.750 x G por $25 \mathrm{~min}$. Os volumes dos sobrenadantes resultantes foram medidos, e o resultado expresso em $\mathrm{mL}$ de óleo/g proteínas.

\section{Capacidade Emulsificante}

Seguiu-se a metodologia de Weeb et al. (1970), Kato et al. (1985) e Hung e Zayas (1991). Quantidades equivalentes a 1,0 mg dos isolados proteicos por $\mathrm{mL}$ de água destilada foram submetidas a postas sob agitação contínua em agitador magnético, em temperatura ambiente. $\mathrm{O} \mathrm{pH}$ foi ajustado para valores de 2,0; 4,0; 5,0,6,0 e 8,0 e, após o equilíbrio ser atingido, prolongou-se o tempo de agitação por 30 minutos. Volumes de $50 \mathrm{~mL}$ das dispersões foram transferidos para o béquer de $250 \mathrm{~mL}$, equipado com eletrodos, conectado a um multímetro para registro de corrente elétrica. Em seguida, as dispersões foram agitadas a 10.000 x G com óleo de soja adicionado em fluxo contínuo de um balão de separação graduado. A quantidade de óleo necessário para que ocorra a inversão da emulsão, foi mensurada a partir do volume acusado no registrador por queda brusca na corrente elétrica, sendo esta medida utilizada para a determinação do volume de óleo necessário para promover a emulsificação, e este, expresso em $\mathrm{mL}$ óleo/100 mg proteínas.

\section{Atividade e Estabilidade de Emulsão}

A atividade e a estabilidade de emulsão foram determinadas segundo o método de Nath e Rao (1981) com modificações. Dispersões dos isolados proteicos equivalentes a $0,5 \mathrm{~g}$ de proteínas em $20 \mathrm{~mL}$ de água destilada foram agitadas em agitador magnético, na temperatura ambiente, e o $\mathrm{pH}$ foi ajustado para valores de 2,0;4,0;5,0;6,0 e 8,0. Adicionaram-se $20,0 \mathrm{~mL}$ de óleo de soja às dispersões, e a emulsão formada a 10.000 x G durante 1 min de agitação foi transferida rapidamente para tubos de centrífuga, sendo centrifugados a $1.388 \mathrm{rpm}$ durante $15 \mathrm{~min}$. $\mathrm{O}$ resultado da atividade de emulsão (AE) foi expresso como percentual de emulsão formada no volume total (Equação 1), e a estabilidade da emulsão, determinada após aquecimento da mesma a $80^{\circ} \mathrm{C}$ por 30 minutos, seguida de resfriamento em gelo por 15 min e centrifugação a 1.388 x G por 15 minutos.

$\mathrm{O}$ resultado da atividade de emulsão (AE) foi expresso como percentual de emulsão formada no volume total, através da equação:

A.E $\%=[($ Altura da camada emulsionada $/$ Altura da camada total )] x 100 (Equação 1)

\section{Análise Estatística}

Foi aplicada a estatística descritiva e atribuiuse a análise do teste "t de Student, "ao nível de 5\% de significância, para a comparação entre as médias obtidas. As análises foram realizadas pelo Programa SPSS 14.0 for Windows Evaluation Version 2, e os dados foram expressos em forma de tabelas.

\section{RESULTADOS E DISCUSSÃO}

\section{Composição Centesimal}

A Tabela 1 apresenta a composição centesimal das amêndoas da munguba. O alto conteúdo de lipídeos e proteínas é a razão maior de as sementes oleaginosas terem vasta aplicação em sistemas alimentícios manufaturados ou por serem utilizadas diretamente na alimentação humana e animal (CAVALCANTI et al., 2009).

Estudos realizados por Oliveira et al. (2000) detectaram para as amêndoas da munguba valores superiores em lipídeos $(53,9 \%)$ e umidade $(6,0 \%)$, inferior em cinza $(3,5 \%)$ e semelhantes para proteína $(12,9 \%)$ e carboidratos $(29,7 \%)$. Jorge e Luzia (2012), ao estudarem a caracterização do óleo das sementes de munguba para aproveitamento alimentar, encontraram valores de $38,39 \%$ para o teor lipídico e $11,86 \%$ para o proteico, respectivamente. As variações nos componentes centesimais podem ser decorrentes das condições de clima, maturação e de semeio da espécie (JORGE; LUZIA, 2012).

O óleo bruto da munguba apresentou-se com uma coloração amarela de baixa intensidade, odor peculiar a sua origem e consistência líquida após a recuperação do solvente. 


\section{Rendimento dos Isolados Proteicos}

Os índices de rendimento na extração e na precipitação verificados no processo de obtenção dos isolados proteicos de amêndoas da munguba constam na Tabela 2.

A partir da farinha desengordurada, 38,52\% das proteínas da munguba no IP 2,0 foram extraídas, e $23,35 \%$ foram precipitadas em relação ao conteúdo proteico da amostra inicial, e o precipitado recuperado por centrifugação resultou num isolado com $78,66 \%$ de proteína.

Para o IP 10,0, 82,06\% de proteínas foram extraídas e $70,94 \%$ foram precipitadas, e o precipitado recuperado resultou num isolado com 92,18\% de proteína, sendo, portanto, a forma mais viável de extração nesse $\mathrm{pH}$. Esta condição observada foi superior para as sementes de feijão-caupi (71,0$86,0 \%$ ) (MUNE et al., 2014) e de castanha de caju (78,8\%) (QUEIROGA NETO et al., 2001). O índice de extração do IP 2,0 (38,52\%) foi comparável ao isolado proteico da semente de goiaba (37\%) (FONTANARI et al., 2007) e inferior para as amêndoas da macadâmia em pH 2,0 de extração (51,80\%) (BORA; RIBEIRO, 2004).

Esses índices revelam a pureza em proteínas dos isolados proteicos, sendo usados para o cálculo da quantidade de isolado a ser utilizado na determinação das propriedades funcionais.

\section{Propriedades Funcionais \\ Solubilidade}

Verifica-se, na Tabela 3, que os isolados proteicos exibiram solubilidade mínima em $\mathrm{pH}$ 5,0, no ponto isoelétrico dessa oleaginosa, e máxima em pH 2,0 (lado ácido) e pH 10,0 (lado alcalino) deste ponto, porém típico das proteínas vegetais que adquirem maior solubilidade nas fases ácida e alcalina da molécula proteica.

O índice de solubilidade de uma molécula proteica proporciona um indício sobre tipos de alimentos e bebidas onde a proteína poderia ser inserida.

Estatisticamente, os isolados proteicos apresentaram-se diferentes em todos os pHs analisados. Esse perfil de solubilidade foi encontrado para as sementes de cupuaçu (Theobroma grandiflorum Schum) (CARVALHO et al., 2006), que exibiram solubilidade mínima na faixa entre $\mathrm{pHs}$ 3,0 e 5,0 ( 10\%), sendo superiores no lado ácido $\mathrm{pH}$ $2,0(\sim 50 \%)$ e alcalino em pH 10,0 ( 90\%). Ramos e Bora (2003), estudando as propriedades funcionais da castanha-do-pará, atingiram ponto isoelétrico em pH 5,0 com um índice de proteínas solúveis de 0,94\% e maior solubilidade em pH 2,0 (77,71\%) e pH 12,0
(87,15\%). Ponto isoelétrico em pH 5,0 com um índice de $4,7 \%$ de proteínas solúveis foi encontrado para o farelo de aveia (GUAN et al., 2006) com solubilidade máxima em $\mathrm{pH}$ 9,0 com $83,2 \%$ de proteínas solúveis. Estudos realizados por Kumar et al. (2014) em Kappaphycus alvarezzi (Doty), uma espécie de macroalga vermelha, detectaram solubilidade de $33,72 \%$, alcançando ponto isoelétrico em $\mathrm{pH} 4,0$, apresentando aumento gradual de solubilidade na faixa de $\mathrm{pH}$ de 8 a 12 .

A solubilidade mínima das proteínas ocorre nas proximidades do $\mathrm{pH}$ isoelétrico. Elas apresentam solubilidade mínima, usualmente em pH 4-5 (pH isoelétrico).

\section{Capacidade de Absorção de Água e de Óleo}

A capacidade de absorção de água do IP 2,0 obteve valor de $1,25 \mathrm{~mL} \mathrm{H}_{2} \mathrm{O} / \mathrm{g}$ proteína e do IP 10,0 atingiu $1,52 \mathrm{~mL} \mathrm{H}_{2} \mathrm{O} / \mathrm{g}$ de proteína, apresentando diferença significativa $(p<0,05)$. A capacidade de absorção de água que as proteínas ou alimentos proteicos possuem está relacionada com a interação proteína-água; com isso, a maior ou menor afinidade entre proteína e água está diretamente ligada à textura, viscosidade, geleificação e emulsificação.

Os valores encontrados para a capacidade de absorção de óleo do IP 2,0 (1,77 mL óleo/g de proteína), em comparação com o IP 10,0 (2,46 $\mathrm{mL}$ óleo/g de proteína), também diferiram significativamente $(\mathrm{p}<0,05)$. A alta capacidade de retenção de óleo é desejável para uso na indústria de carnes frias, particularmente para salsichas, onde a proteína pode preencher a gordura e a água nestes produtos (OGUNWOLU et al., 2009).

Em sistemas alimentares, boas interações de água e óleo com proteínas são fundamentais, pois isso afetaria indiretamente o sabor e a textura dos alimentos. Entretanto, os métodos de processamento de alimentos têm importantes impactos sobre a conformação da proteína e a hidrofobicidade (KUMAR et al., 2014) .

\section{Capacidade Emulsificante}

As capacidades emulsificantes dos isolados proteicos IP 2,0 e IP 10,0 foram dependentes do $\mathrm{pH}$ e notou-se menor capacidade de emulsificação no ponto isoelétrico $(5,0)$, sendo maior nos lados ácido e alcalino desse ponto.

As capacidades emulsificantes dos isolados proteicos IP 2,0 e IP 10,0, em função do pH, estão representadas na Tabela 4.

Para os dois isolados (IP 2,0 e IP10,0), a capacidade emulsificante foi maior em $\mathrm{pH} 8,0$. Para o IP 10,0, foi de 100,32 mL óleo/100 mg de 
proteína, e para o IP 2,0, foi de 94,78 mL óleo/100 $\mathrm{mg}$ de proteína, diferindo estatisticamente entre si $(\mathrm{p}<0,05)$. No entanto, em $\mathrm{pH} 2,0$, foi verificada uma capacidade de 78,18 mL óleo/100 mg de proteína para o IP 10,0, e de 65,14 mL óleo/100 mg de proteína para o IP 2,0, e também apresentando significância quanto à diferença nos resultados $(\mathrm{p}<0,05)$. A maior capacidade emulsificante foi verificada pelo IP 10,0 (100,32 mL óleo/100 mg de proteína) em pH 8,0, e a menor foi para o IP 2,0 (25,13 mL óleo/ $100 \mathrm{mg}$ de proteína) em pH 5,0. Estes valores mostraram-se superiores a K. alvarezzi (Doty) com $38 \mathrm{~mL} /$ óleo/100 mg de proteína em pH 4,0 (KUMAR et al., 2014) e Enteromorpha compressa com $55 \mathrm{~mL}$ óleo/100 mg de proteína em pH 14,0 (GANESAN et al., 2012).

As propriedades emulsificantes de uma proteína não dependem somente da solubilidade, mas também do balanço hidrofílico de cada proteína (EL NARSI; EL TINAY, 2007).

\section{Atividade e Estabilidade de Emulsão}

A atividade e a estabilidade de emulsão dos isolados proteicos IP 2,0 e IP 10,0 foram dependentes do $\mathrm{pH}$, como mostra a Tabela 5 .

A menor atividade e a menor estabilidade de emulsão dos isolados proteicos foram observadas em $\mathrm{pH} 5,0$, atribuídas ao fato de as proteínas dos isolados estarem na faixa de $\mathrm{pH}$ isoelétrico. No entanto, foi observada maior atividade e estabilidade de emulsão em pHs 2,0 e 8,0, em que acontece maior solubilidade das proteínas, onde as forças repulsivas eletrostáticas e o balanço de forças atrativas de Van der Waals contribuem com essa propriedade.

A AE não diferiu estatisticamente da EE nos isolados proteicos avaliados, com exceção do IP 2,0 em pH 4,0 e de IP 10,0 em pH 6,0, onde a atividade de emulsão foi superior à EE.

No IP 2,0, em pH 5,0, no ponto isoelétrico, a AE foi de 5,38\% e a EE de 5,01\%; já em pH 8,0, um percentual de $56,45 \%$ para $\mathrm{AE}$ e de $55,42 \%$ para a EE foram observados. Estes resultados, de acordo com a Tabela 5, não se diferenciam estatisticamente $(\mathrm{p}<0,05)$.

O IP 10,0, em pH 2,0, exibiu uma AE de $54,84 \%$ e uma EE de 53,27\%; logo, em pH 5,0 no ponto isoelétrico, a AE foi de $6,45 \%$ e a EE de $5,97 \%$, respectivamente. Em pH 8,0, verificou-se um percentual de $58,54 \%$ para AE e de $57,93 \%$ para EE, não diferindo estatisticamente $(\mathrm{p}<0,05)$.

Comportamentos semelhantes para a atividade e a estabilidade de emulsão foram encontrados para as amêndoas de macadâmia (BORA; RIBEIRO, 2004), sementes de cupuaçu (Theobroma grandiflorum Schum) (CARVALHO et al., 2006) e sementes de goiaba (Psidium guajava) (FONTANARI et al., 2007).

TABELA 1 - Composição centesimal de amêndoas da munguba (Pachira aquatica Aubl.).

\begin{tabular}{lc}
\hline \multicolumn{1}{c}{ Componentes } & Teor (\%) \\
\hline Umidade & $5,53 \pm 0,09$ \\
Cinza & $4,89 \pm 0,09$ \\
Lipídeos & $46,62 \pm 0,85$ \\
Proteínas $(\mathrm{N} \mathrm{x} \mathrm{6,25)}$ & $13,75 \pm 0,46$ \\
Carboidratos * & 29,20 \\
\hline
\end{tabular}

*Carboidratos por diferença (100 menos o somatório dos demais componentes). Resultados das análises com média e desvio-padrão de cinco repetições.

TABELA 2 - Extração e recuperação de proteínas na obtenção dos isolados proteicos de $100 \mathrm{~g}$ da farinha desengordurada de amêndoas da munguba (Pachira aquatica Aubl.).

\begin{tabular}{|c|c|c|c|c|}
\hline \multicolumn{5}{|c|}{ ISOLADO PROTEICO } \\
\hline & IP 2,0 & & IP 10,0 & \\
\hline & Massa (g) & $(\%)$ & Massa (g) & $(\%)$ \\
\hline $\begin{array}{l}\text { Proteína Total na Farinha } \\
\text { Desengordurada }(\mathrm{N} \times 6,25)\end{array}$ & $28,27 \pm 0,25 \mathrm{a}$ & 100 & $28,27 \pm 0,25 a$ & 100 \\
\hline Proteína Extraída & $10,89 \pm 0,60 \mathrm{a}$ & 38,52 & $23,20 \pm 0,55 b$ & 82,06 \\
\hline Precipitação Isoelétrica & $6,60 \pm 0,20 \mathrm{a}$ & 23,35 & $20,05 \pm 0,93 b$ & 70,94 \\
\hline Proteína não Precipitada & $4,30 \pm 0,69 \mathrm{a}$ & 15,17 & $3,14 \pm 0,20 b$ & 11,12 \\
\hline Proteína não Extraída & $17,38 \pm 0,66 \mathrm{a}$ & 61,48 & $5,07 \pm 0,58 b$ & 17,94 \\
\hline
\end{tabular}

Resultados das análises com média e desvio-padrão de cinco repetições. Letras diferentes na mesma linha diferem significativamente, de acordo com o teste t-student, ao nível de $5 \%$ de probabilidade.

Legenda: IP 2,0 - isolado proteico em pH 2,0; IP 10,0 - isolado proteico em $\mathrm{pH}$ 10,0. 
TABELA 3 - Percentual de proteínas solúveis (g/100 g) dos isolados proteicos (IP 2,0) e (IP 10,0) de amêndoas da munguba (Pachira aquatica Aubl.) em diferentes níveis de $\mathrm{pH}$.

\begin{tabular}{ccc}
\hline PH DA SUSPENSÃO & IP 2,0 & IP 10,0 \\
\hline 2,0 & $54,00 \pm 1,00 \mathrm{a}$ & $67,00 \pm 0,50 \mathrm{~b}$ \\
4,0 & $21,75 \pm 0,52 \mathrm{a}$ & $31,96 \pm 1,00 \mathrm{~b}$ \\
5,0 & $15,10 \pm 0,35 \mathrm{a}$ & $17,60 \pm 0,82 \mathrm{~b}$ \\
6,0 & $25,90 \pm 0,70 \mathrm{a}$ & $27,40 \pm 0,16 \mathrm{~b}$ \\
8,0 & $45,20 \pm 0,92 \mathrm{a}$ & $48,10 \pm 0,96 \mathrm{~b}$ \\
10,0 & $75,60 \pm 0,86 \mathrm{a}$ & $78,90 \pm 0,69 \mathrm{~b}$ \\
\hline
\end{tabular}

Resultados das análises com média e desvio-padrão de três repetições. Letras diferentes na mesma linha diferem significativamente, de acordo com o teste t-student,ao nível de $5 \%$ de probabilidade.

Legenda: IP 2,0 - isolado proteico em $\mathrm{pH}$ 2,0; IP 10,0 - isolado proteico em $\mathrm{pH}$ 10,0.

TABELA 4 - Capacidade emulsificante dos isolados proteicos de amêndoas da munguba (Pachira aquatica Aubl.) em diferentes níveis de $\mathrm{pH}$, expressa em $\mathrm{mL}$ de óleo/100 mg de proteína.

\begin{tabular}{ccc}
\hline PH DA SUSPENSÃO & IP 2,0 & IP 10,0 \\
\hline 2,0 & $65,14 \pm 0,03 \mathrm{a}$ & $78,18 \pm 0,27 \mathrm{~b}$ \\
4,0 & $44,97 \pm 0,02 \mathrm{a}$ & $48,47 \pm 0,16 \mathrm{~b}$ \\
5,0 & $25,13 \pm 0,02 \mathrm{a}$ & $31,86 \pm 0,32 \mathrm{~b}$ \\
6,0 & $60,48 \pm 0,52 \mathrm{a}$ & $65,48 \pm 0,45 \mathrm{~b}$ \\
8,0 & $94,78 \pm 0,56 \mathrm{a}$ & $100,32 \pm 0,10 \mathrm{~b}$ \\
\hline
\end{tabular}

Resultados das análises com média e desvio-padrão de três repetições.Letras diferentes na mesma linha diferem significativamente, de acordo com o teste t-student, ao nível de $5 \%$ de probabilidade.

Legenda: IP 2,0 - isolado proteico em $\mathrm{pH}$ 2,0; IP 10,0 - isolado proteico em pH 10,0.

TABELA 5 - Atividade e estabilidade de emulsão dos isolados proteicos de amêndoas da munguba (Pachira aquatica Aubl.) em diferentes níveis de $\mathrm{pH}$.

\begin{tabular}{cccc}
\hline $\begin{array}{c}\text { ISOLADOS } \\
\text { PROTEICOS }\end{array}$ & pH DA SUSPENSÃO & $\begin{array}{c}\text { ATIVIDADE DE } \\
\text { EMULSÃO \% } \\
\text { (AE) }\end{array}$ & $\begin{array}{c}\text { ESTABILIDADE } \\
\text { EMULSÃO (\%) } \\
\text { (EE) }\end{array}$ \\
\hline & 2,0 & $40,05 \pm 0,05 \mathrm{a}$ & $39,00 \pm 0,50 \mathrm{a}$ \\
IP 2,0 & 4,0 & $29,66 \pm 0,28 \mathrm{a}$ & $27,50 \pm 0,50 \mathrm{~b}$ \\
& 5,0 & $5,38 \pm 0,54 \mathrm{a}$ & $5,01 \pm 0,77 \mathrm{a}$ \\
& 6,0 & $36,48 \pm 0,47 \mathrm{a}$ & $35,65 \pm 0,58 \mathrm{a}$ \\
& 8,0 & $56,45 \pm 0,13 \mathrm{a}$ & $55,42 \pm 0,39 \mathrm{a}$ \\
IP 10,0 & 4,0 & $54,84 \pm 0,26 \mathrm{~b}$ & $53,27 \pm 0,24 \mathrm{~b}$ \\
& 5,0 & $36,60 \pm 0,79 \mathrm{~b}$ & $35,70 \pm 0,26 \mathrm{~b}$ \\
& 6,0 & $6,45 \pm 0,37 \mathrm{~b}$ & $5,97 \pm 0,17 \mathrm{~b}$ \\
& 8,0 & $47,49 \pm 1,00 \mathrm{~b}$ & $45,26 \pm 0,25 \mathrm{a}$ \\
& $58,54 \pm 0,26 \mathrm{~b}$ & $57,93 \pm 0,2 \mathrm{~b}$ \\
\hline
\end{tabular}

Resultados das análises com média e desvio-padrão de três repetições.Letras diferentes na mesma linha diferem significativamente, de acordo com o teste t-student, ao nível de $5 \%$ de probabilidade.

Legenda: IP 2,0 - isolado proteico em pH 2,0; IP 10,0 - isolado proteico em pH 10,0. 


\section{CONCLUSÕES}

As sementes de Pachira aquatica Aubl. mostraram-se promissoras quanto ao teor lipídico e proteico, constituindo-se como fonte para a exploração econômica.

O melhor rendimento da extração dos isolados proteicos foi para o IP 10,0, portanto, a forma mais viável de extração, confirmando sua performance na funcionalidade proteica ao confrontar-se com o IP 2,0.

$\mathrm{O}$ índice de solubilidade mais apropriado foi observado para o IP 10,0, indicando o uso em produtos de panificação, massas em geral, bebidas, sopas desidratadas, molhos e alimentos semissólidos. Quanto às CAAs e à $\mathrm{CAO}$, estas foram melhores no IP 10,0 e apenas de absorção de óleo no IP 2,0, beneficiando a aplicação em carnes simuladas, salsichas, linguiças, patês, massas e bolos. No que se refere às propriedades emulsificantes, o IP 10,0 também apresentou os melhores resultados, porém mais conveniente o uso em alimentos com elevado poder de emulsificação, tipo maionese, e em emulsões cárneas, como também seu uso em sorvetes.

Sugerem-se, então, estudos posteriores no sentido de aplicar a funcionalidade desses isolados proteicos em sistemas alimentares.

\section{AGRADECIMENTOS}

Agradecemos à CAPES e ao CNPQ, pela colaboração para o desenvolvimento deste estudo.

\section{REFERÊNCIAS}

AOAC. Official methods of analysis of the Association Analytical Chemists. $18^{\text {th }}$ ed. Gaithersburg, 2005.

BENCINI, M. C. Functional properties of drum dried chickpea (Cicer arietinum L.) flour. Journal of Food Science,Chicago, v.51, n.6, p.1518-1526, 1986.

BERA, M. B.; MUKHERJEE, R. K. Solubility, emulsifying, and foaming properties of rice bran protein concentrates. Journal of Food Science, Chicago, v.54, p.142-145, 1989.

BORA, P. S.; RIBEIRO, D. Influence of $\mathrm{pH}$ on the extraction yield and functional properties of macadamia (Macadamia integrofolia) protein isolates. Food Science and Technology International, London, v.10, n.4, p.263-267, 2004.
CARVALHO, A. V.; GARCIA, N. H. P.; FARFAN, A. J. Physico-chemical properties of the flour, protein concentrate, and protein isolate of the cupuassu (Theobroma grandiflorum Schum) seed. Journal of Food Science, Chicago, v.71, n.8, p.573-578, 2006.

CAVAlCANTI, M. T.; BORA, P. S.; CARVAJAL, J. C. L. Propriedades funcionais das proteínas de amêndoas da faveleira (Cnidosculus phyllacanthus (Mart.) Pax. Et K. Hoffm.) com e sem espinhos. Ciência e Tecnologia de Alimentos, Campinas, v. 29, n. 3 p.597-602, 2009.

CHEL-GUERRERO, L.; PÉREZ-FLORES, V.; BETANCUR-ANCONA, D.; DÁVILA-ORTIZ, G. Functional properties of flours and protein isolates from Phaseolus lunatus and Canavalia ensiformis seeds. Journal of Agricultural and Food Chemistry, Easton, v. 50, n.3, p.584-591, 2002.

EL NASRI, N. A.; EL TINAY, A. H. Functional properties of fenugreek (Trigonella foenum graecum) protein concentrate. Food Chemistry, London, v.103, p.582-589, 2007.

FONTANARI, G. G.; JACON, M. C.; PASTRE, I. A.; FERTONANI, F.L.; NEVES, V. A.; BATISTUTI, J.P. 2007. Isolado proteico de semente de goiaba (Psidium guajava): caracterização de propriedades funcionais. Ciência e Tecnologia de Alimentos, Campinas, v. 27, p.73-79, 2007.

GANESAN, K.; KUMAR, K. S.; SUBBA RAO, P. $\mathrm{V}$. Salt and $\mathrm{pH}$ induced functional changes in protein concentrate of edible green seaweed Enteromorpha species. Fisheries Science, Tokyo, v.78, p.169-176, 2012.

GUAN, X.; YAO, H.; CHEN, Z.; SHAN, L.; ZHANG, M. Some functional properties of oat bran protein concentrate modifed by trypsin. Food Chemistry, London, v. 101, n.1, p.163-170, 2006.

HUNG, C. R.; ZAYAS, J. F. Water retention and solubility of soy proteins and corn germ proteins in a model system. Journal of Food Science, Chicago, v. 56, n.2, p. 455-458, 1991.

JORGE, N.; LUZIA, D. M. M. Caracterização do óleo das sementes de Pachira aquatica Aublet para aproveitamento alimentar. Acta Amazônica, Manaus, v. 42, n.1, p.149-156, 2012. 
KATO, A.; TAKAHASHI A.; MATSUDOMI, N.; KOBAYASHI, K. Determination of emulsifying properties of some proteins by conductivity measurements. Journal of Food Science, Chicago, v.50, n.1, p.50-62, 1985.

KUMAR, K.S.; GANESAN, K.; SELVARAJ, K.; SUBBA RAO, P. V. Studies on the functional properties of protein concentrate of Kappaphycus alvarezii (Doty) - An edible seaweed. Food Chemistry, London, v.153 p.353-360, 2014.

LIN, C. S.; ZAYAS, J. F. Functionality of defatted corn germ protein in a model system: fat binding capacity and water retention. Journal of Food Science, Chicago, v.52, n.5, p.1308-1311, 1987.

MAKRI, E.; PAPALAMPROU, E.; DOXASTAKIS, G. Study of functional properties of seed storage proteins from indigenous European legume crops (lupin, pea, broad bean) in admixture with polysaccharides. Food Hydrocolloids. Netherlands, v.19, p.583-594, 2005.

MUNE, M.A.M.; MINKA, S.R.; MBOME, I.L. Optimizing functional properties during preparation of cowpea protein concentrate. Food Chemistry, London, v.154, p.32-37, 2014. Doi: http://dx.doi. org/10.1016/j.foodchem. 2013.12.108, 2014

NATH, J. P.; RAO, M. S. N. Functional properties of guar proteins. Journal of Food Science, Chicago, v.46, n.4, p.1255-1259, 1981.

OGUNWOLU, S. O.; HENSHAW, F. O.; MOCK, H. P.; SANTROS, A. Functional properties of protein concentrates and isolates produced from cashew (Anacardium occidentale L.) nut. Food Chemistry, London, v.115, n.3, p.852-858, 2009.

OLIVEIRA, J. T. A.; VASCONCELOS, I. M.; BEZERRA, L. C. N. M.; SILVEIRA, S. B.; MONTEIRO, A. C. O.; MOREIRA, R. A. Composition and nutritional properties of seeds Pachira aquatica Aubl, Sterculia striata St Hil et Naud and Terminalia catappa Linn. Food Chemistry, London, v.70, n.1, p.185-191, 2000.
PEIXOTO, A. L.; ESCUDEIRO, A. Pachira aquatica (Bombacaceae) na obra "história dos Animais e Árvores do Maranhão" de Frei Cristóvão de Lisboa. Rodriguésia, Rio de Janeiro, v.53, n.82, p.123-130, 2002.

QUEIROGA NETO, V.; NARAIN, N.; SILVA, J. B.; BORA, P. S. Functional properties of raw and heat processed cashew nut (Anacardium occidentale, L.) kernel protein isolates. Nahrung, Berlin, v.45, n.4, p. 258-262, 2001.

RAMOS, C. M. P.; BORA, P. S. B. Extraction and characteristics of Brazil nut (Bertholletia excelsa HBK) globulin. Food Science and Technology International, London, v.9, n. 4, p.265-270, 2003.

RODRIGUES, I. V.; COELHO J. F. J.; CARVALHO, M. G. V. S. Isolation and valorization of vegetable proteins from oilseed plants: methods, limitations and potential. Journal of Food Engineering, Essex, v.109, p.337-346, 2012.

WEEB, N. B.; IVEY, F. J.; CRIC, H. B. The measurement of emulsifying capacity by electrical resistence. Journal of Food Science, Chicago, v.35, n.2, p. 501-504, 1970.

YUN, J. H.; KWON, I. K.; LOHAKARE, J. D.; CHOI, J. Y.; YONG, J. S.; ZHENG, J. Comparative efficacy of plant and animal protein sources on the growth performance, nutrient digestibility, morphology and caecal microbiology of earlyweaned pigs. Asian - Australasian Journal of Animal Sciences, Seoul, v. 18, p.1285-1293, 2005. 